Bull. Mater. Sci., Vol. 22, No. 5, August 1999, pp. 933-936. (C Indian Academy of Sciences.

\title{
Fatigue crack growth behaviour of gamma base titanium aluminides under different loading conditions
}

\author{
R GNANAMOORTHY* and Y MUTOH ${ }^{\dagger}$ \\ Department of Mechanical Engineering, Indian Institute of Technology, Chennai 600 036, India \\ Department of Mechanical Engineering, Nagaoka University of Technology, Nagaoka-shi 940-2188, Japan
}

MS received 16 November 1998; revised 29 May 1999

\begin{abstract}
Static and cyclic fatigue crack growth behaviour of gamma base titanium aluminides with three different microstructures were investigated. Influence of cyclic test frequency on fatigue crack growth behaviour was also studied at room temperature under a controlled humidity condition. The crack growth behaviour both under static and cyclic loading was strongly influenced by the microstructure. The threshold stress intensity and crack growth behaviour under cyclic loading were much inferior than that under static loading indicating the 'true-cyclic fatigue' effect exhibited in gamma base titanium aluminides. No significant effect of test frequency on the crack growth behaviour was observed for the equiaxed and duplex microstructure materials.
\end{abstract}

Keywords. Titanium aluminide; fatigue crack growth; static fatigue; cyclic fatigue; frequency; microstructure.

\section{Introduction}

Gamma base titanium aluminides are promising materials for high-temperature structural applications in aerospace and automobile industries because of their excellent hightemperature strength, modulus retention at elevated temperatures, oxidation resistance and low density (Lipsitt 1985; Kim 1989). However, their commercial application is hindered due to poor ductility, low fracture toughness and inferior fatigue crack growth properties. Extensive research has led to a considerable improvement in these inferior properties. Ductility as high as $5 \%$ and fracture toughness as high as $35 \mathrm{MPa} \sqrt{\mathrm{m}}$ has been achieved by microstructural modifications, alloying additions and improved thermo-mechanical processing techniques. However very less is known about the fatigue crack growth behaviour of these materials (Aswanth et al 1990; Davidson and Campbell 1993). It is found that titanium aluminides are also susceptible to environmental embrittlement similar to conventional titanium alloys (Nakamura and Kaieda 1990; Chan and Kim 1993; Gnanamoorthy et al 1995a). As these materials are considered for application in severe environments their resistance to environmental embrittlement needs to be improved and a detailed study is very essential. In practice these materials are also suggested for structural applications subjected to static loading in addition to cyclic loading situations. Therefore it is necessary to study the behaviour of

*Author for correspondence materials under constant static loading, cyclic loading with different loading frequencies and investigate the mechanisms of crack growth. This paper presents the results of the static and cyclic crack growth behaviour studies on gamma base titanium aluminides with three different microstructures.

\section{Materials and experimental}

Titanium aluminide base intermetallic compounds with three different microstructures used in the present study were cast in a plasma arc melting furnace using high purity raw materials. All the materials were heat treated for $96 \mathrm{~h}$ at $1050^{\circ} \mathrm{C}$ in a vacuum of better than $1.3 \times 10^{-3} \mathrm{~Pa}$. The chemical composition of test materials is shown in table 1 . Binary Ti-50Al (all compositions are mentioned in atomic percent unless specified) had an equiaxed microstructure with a grain size of about $200 \mu \mathrm{m}$ and $\mathrm{Ti}-46 \mathrm{Al}$ resulted in a lamellar microstructure with a coarse grain size of about $400 \mu \mathrm{m}$ (figure 1). The duplex refined microstructure with a mixture of equiaxed and lamellar grains was obtained by the addition of $3 \%$ chromium and the heat treatment under the above condition.

Crack growth studies under static loading were performed using single edge notched three-point bend specimens of dimensions $5 \mathrm{~mm} \times 10 \mathrm{~mm} \times 55 \mathrm{~mm}$. Tests were carried out on the fatigue pre-cracked specimens using a servo hydraulic machine operated in load control up to $2 \mathrm{~mm}$ in air at $20^{\circ} \mathrm{C}$ and controlled relative humidity of $55 \%$. The maximum stress intensity used in the 
pre-cracking was kept well below the critical stress intensity factor of the material. The crack length was measured directly using a travelling microscope with an accuracy of $10 \mu \mathrm{m}$. The applied stress intensity was increased by $0.2 \mathrm{MPa} \sqrt{\mathrm{m}}$ if no crack growth was observed even after several hours. The crack was allowed to grow few millimetres and then the applied stress intensity was reduced. The threshold stress intensity was determined by gradually reducing the applied stress intensity.

Cyclic fatigue crack growth experiments were performed using the specimens of same dimensions as static crack growth experiments. Fatigue crack growth data were generated from the fatigue pre-cracked specimens using a servo-hydraulic test machine for the low test frequencies $(0.01 \mathrm{~Hz}, 1 \mathrm{~Hz}$ and $10 \mathrm{~Hz})$ and using the piezoelectric test machine for high test frequency (166 $\mathrm{Hz}$ ). Tests were performed at a constant stress ratio $\mathrm{R}$ of $0 \cdot 1$. The threshold stress intensity factor range was determined using load shedding technique. All cyclic fatigue crack growth experiments were performed at $20^{\circ} \mathrm{C}$ in controlled relative humidity of $55 \%$. Fatigue crack lengths were measured using the travelling microscope.

Fatigue crack path and fracture surfaces were analyzed using optical and scanning electron microscopes.

\section{Results and discussion}

The static and cyclic crack growth data are shown in figure 2 for the materials investigated. The crack growth rate per cycle in cyclic test data is converted into crack growth rate per sec using the corresponding frequency used. From this figure it is obvious that the crack growth behaviour of gamma base titanium aluminides strongly depended on the microstructure. The threshold values for crack growth varied from $6.1 \mathrm{MPa} \sqrt{\mathrm{m}}$ to $17.0 \mathrm{MPa} \sqrt{\mathrm{m}}$ depending upon the microstructure and type of loading (table 2). The constant, $m$, of the Paris equation,

$$
\mathrm{d} a / \mathrm{d} N=C(\Delta K)^{m},
$$

is also shown in this table for the test materials under static and cyclic loading conditions. From this figure it is also clear that the crack growth behaviour under cyclic loading is quite different from that under static loading for equiaxed and duplex microstructure materials. The

Table 1. Chemical composition of test materials.

\begin{tabular}{|c|c|c|c|c|c|c|}
\hline \multirow[b]{3}{*}{ Material } & \multicolumn{6}{|c|}{ Chemical composition } \\
\hline & \multicolumn{3}{|c|}{ Atomic (\%) } & \multicolumn{3}{|c|}{ Weight (ppm) } \\
\hline & $\mathrm{Ti}$ & $\mathrm{Al}$ & $\mathrm{Cr}$ & $\mathrm{O}$ & $\mathbf{H}$ & $\mathrm{C}$ \\
\hline Ti-50AI & $49 \cdot 1$ & 50.9 & - & 170 & 5.0 & 70 \\
\hline $\mathrm{Ti}-47 \mathrm{Al}-3 \mathrm{Cr}$ & $48 \cdot 1$ & 49.2 & 2.75 & 250 & 7.0 & 120 \\
\hline $\mathrm{Ti}-46 \mathrm{Al}$ & 55.3 & 44.7 & - & 120 & 1.6 & $<30$ \\
\hline
\end{tabular}

constant, $m$, for all titanium aluminides investigated was very high compared to ductile metallic materials which ranges from 2 to 4 (Ritchie 1979). The slopes also indicate rapid crack growth under static loading compared to cyclic loading. Crack growth occurred at low applied stress intensity factors under cyclic loading and the threshold stress intensity factor was also very low compared to that under static loading. However for the lamellar coarse grain microstructure there is a wide scatter in the test data.
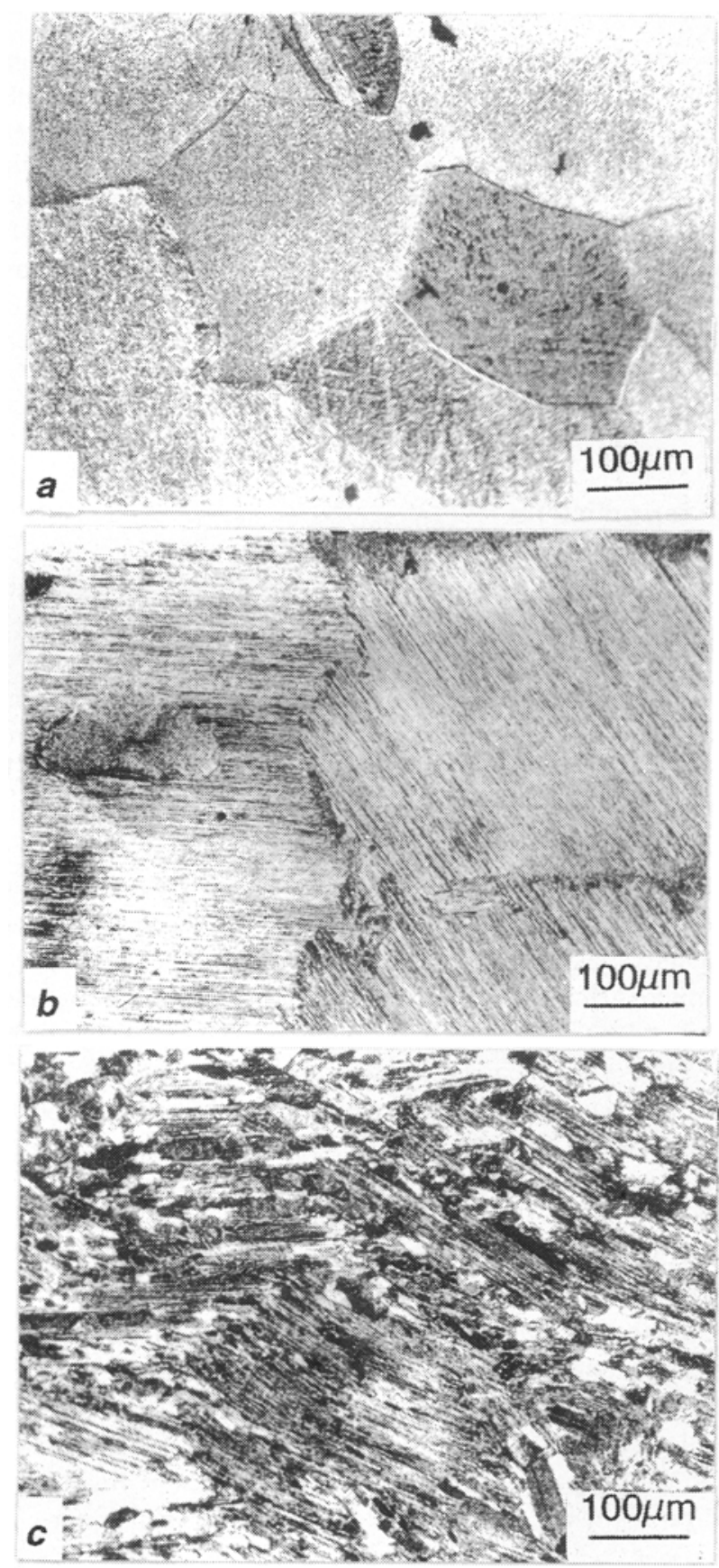

Figure 1. Optical microstructures of cast and heat-treated materials. a. Ti-50Al, b. Ti-46Al and c. Ti-47Al-3Cr. 
The crack growth behaviour of these materials strongly depended on the orientation of the lamellar lath to the crack growth direction. When the crack grows parallel to the laths i.e. along the weak lamellar interfaces, fast crack growth occurred. In addition, the ratio of number of grains to the specimen width is also too low in this material and this will also cause a wide scatter in the crack growth data.

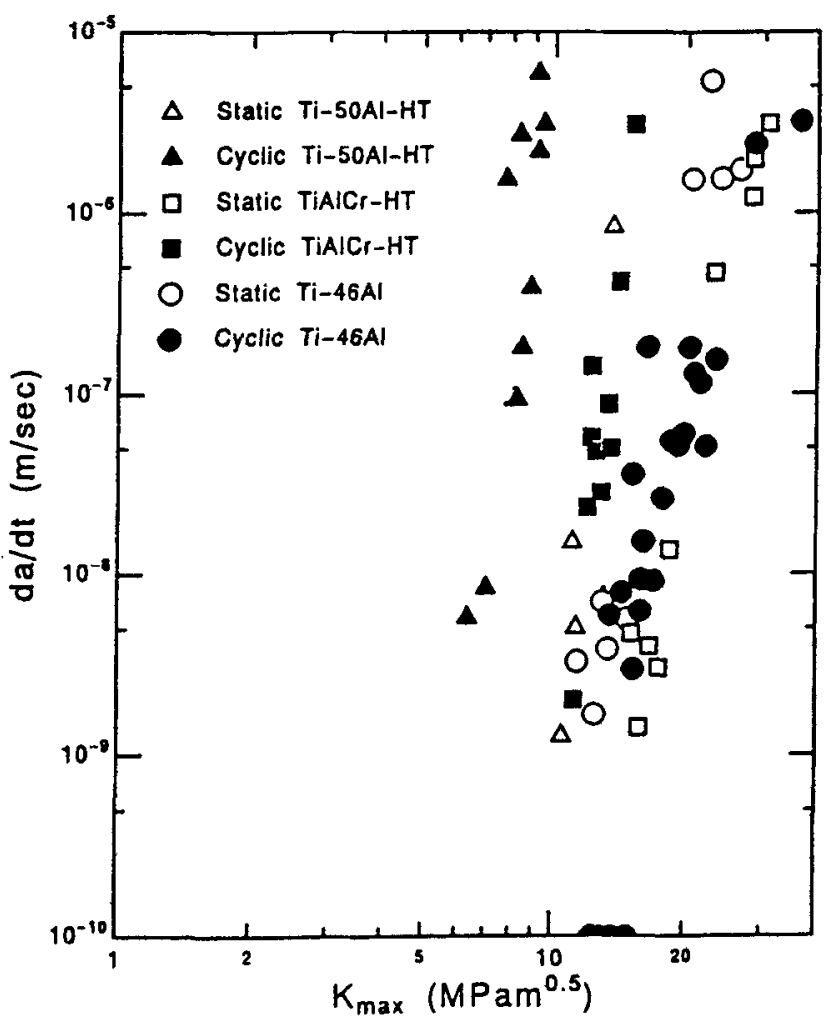

Figure 2. Fatigue crack growth behaviour of cast and heattreated gamma base titanium aluminides under static and cyclic loading (frequency $=10 \mathrm{~Hz}$ ) conditions.
The crack growth under static loading for gamma base titanium aluminides was attributed mainly to the stress corrosion cracking (Gnanamoorthy et al 1995b). Presence of the embrittling species in the atmosphere embrittles the crack tip material and results in the high crack growth rates similar to conventional titanium alloys (Paton and Williams 1974). This effect depends on the microstructure and alloying additives (Gnanamoorthy et al 1995b).

The influence of test frequency on the crack growth behaviour of test materials is shown in figure 3. For $\mathrm{Ti}-50 \mathrm{Al}$ and $\mathrm{Ti}-47 \mathrm{Al}-3 \mathrm{Cr}$ investigated, no effect on the crack growth rate was observed even by varying the cyclic frequency from $0.01 \mathrm{~Hz}$ to $10 \mathrm{~Hz}$. Although the gamma base titanium aluminides show severe environmental embrittlement as discussed earlier, the lack of response of the material to the current study may be attributed to two reasons. High levels of crack closure were observed in the gamma base titanium aluminides due to crack branching, blunting, microcrack toughening and bridging mechanisms (Gnanamoorthy et al 1996). The high levels of crack closure results in the closure of crack tip for most of the time in each cycle and the active surfaces are not exposed to the embrittling species for most part of the cycle. Secondly a wide scatter in the experimental data in cyclic loading conditions does not reveal the negligible effects of environmental species. For the Ti-46Al investigated there is a wide scatter in the data and it is difficult

Table 2. Fatigue threshold stress intensity factor and Paris constant, $m$ under static and cyclic loading.

\begin{tabular}{lcccccc}
\hline & \multicolumn{2}{c}{$\begin{array}{c}\text { Fatigue threshold stress } \\
\text { intensity }(\mathrm{MPa} V \mathrm{~m})\end{array}$} & & \multicolumn{2}{c}{$\begin{array}{c}\text { Paris constant } \\
(m)\end{array}$} \\
\cline { 2 - 3 } \cline { 5 - 6 } & $\begin{array}{c}\text { Static } \\
\text { loading }\end{array}$ & $\begin{array}{c}\text { Cyclic } \\
\text { loading }\end{array}$ & & $\begin{array}{c}\text { Static } \\
\text { loading }\end{array}$ & $\begin{array}{c}\text { Cyclic } \\
\text { loading }\end{array}$ \\
\hline Material & 10.5 & 6.1 & & 21.2 & 16.9 \\
Ti-50Al & 15.2 & 10.0 & & 15.5 & 10.4 \\
Ti-47Al-3Cr & 15.2 & 13.3 & 8.3 \\
Ti-46Al & $11.4-17.0$ & $10.1-15.8$ & & 13.3 \\
\hline
\end{tabular}

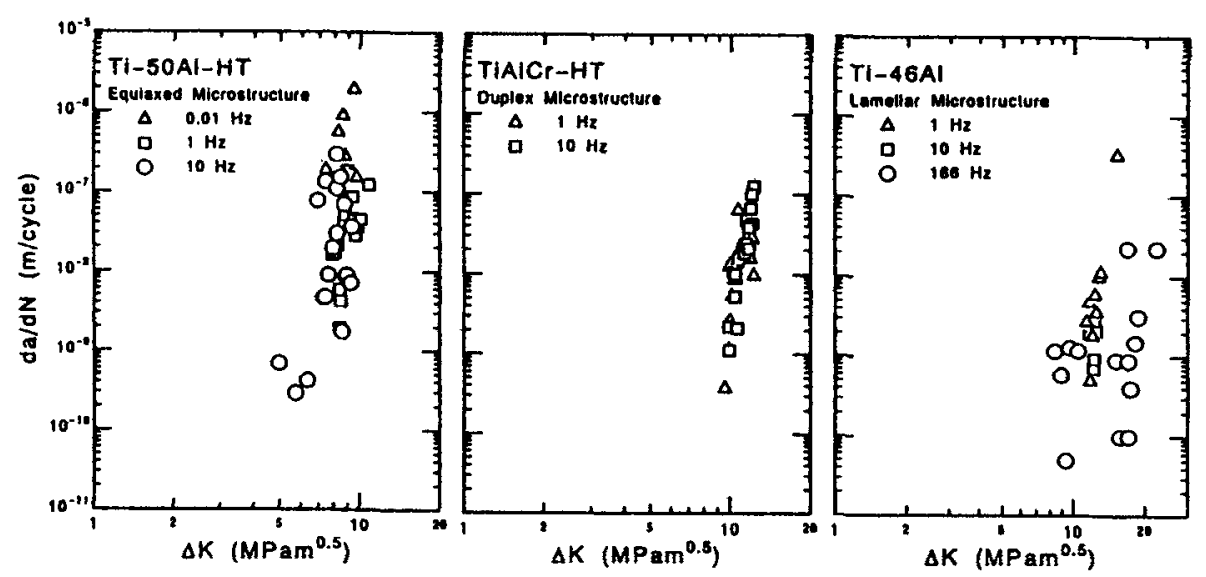

Figure 3. Influence of cyclic test frequency on the cyclic crack growth behaviour of test materials. 
to conclude from the present results about the influence of the test frequency. The wide scatter in the test data is due to the influence of the lath orientation and large grain size as discussed earlier.

The considerable difference in the crack growth behaviour of gamma base titanium aluminides under static and cyclic loading in the present study indicates that these materials exhibit a true cyclic fatigue effect similar to ceramic materials (Kishimoto et al 1990). The crack growth under cyclic loading is not just the cyclic manifestation of stress corrosion cracking as the crack grew at a lower stress intensity factor under cyclic loading conditions and with low threshold stress intensity. In addition no significant influence of test frequency also validates the above conclusion. Similar results were observed in superalloys (Weerasooriya 1988) and alphatwo base titanium aluminides (Pernot et al 1995). For the Inconel 718 superalloys, there is a critical frequency above which frequency no longer influences the fatigue crack growth behaviour and the behaviour is generally categorized as purely cyclic dependent. Effect of frequency on the crack growth behaviour of Ti-24Al$11 \mathrm{Nb}$ was reported at high temperatures and at lower temperatures no effect of frequency was observed (Pernot et al 1995). Gamma base titanium aluminides also behave in a similar manner exhibiting cycle-dependent crack growth behaviour at room temperature.

\section{Conclusions}

The static and cyclic crack growth behaviours of gamma base titanium aluminides were investigated. The crack growth behaviour under static and cyclic loading strongly depended on the microstructure of material. Crack growth under cyclic loading was inferior to that under static loading and with a lower threshold stress intensity factor. No significant influence of loading frequency was observed on the crack growth behaviour. The gamma base titanium aluminides exhibit 'cycle dependent' crack growth behaviour at room temperature.

\section{Acknowledgements}

The research work was carried out at the Nagaoka University of Technology, Japan. Support from the Ministry of Education, Science and Culture, Government of Japan to one of the authors (RG) during the course of research is gratefully acknowledged. The authors are also indebted to Nippon Steel Corp. for preparing specimens and valuable discussions.

\section{References}

Aswanth P B, Soboyejo W O and Suresh S 1990 in Fatigue'90 (Warley: Materials and Component Engineering Publications) Chan K S and Kim Y W 1993 Metall. Trans. A24 113

Davidson D L and Campbell J B 1993 Metall. Trans. A24 1555

Gnanamoorthy R, Mutoh Y and Mizuhara Y 1995a Mater. Sci. \& Eng. A19435

Gnanamoorthy R, Mutoh Y and Mizuhara Y 1995b Mater. Sci. \& Eng. A203 348

Gnanamoorthy R, Mutoh $Y$ and Mizuhara $Y 1996$ intermetallics 4525

Kim Y W 1989 J. Metals 4124

Kishimoto H, Ueno A and Kawamoto H 1990 in Fatigue 90 (Warley: Materials and Component Engineering Publications)

Lipsitt H A 1985 Mater. Res. Soc. Symp. Proc. 39351

Nakamura M and Kaieda Y 1990 Powder Metall. A33 133

Paton N E and Williams J C 1974 in Effects of hydrogen on materials properties and selection on structural design (Ohio, USA: American Society for Metals)

Pernot J J, Mall S and Nicholas T 1995 Trans ASME; J. Engg. Matls. and Tech. 117118

Ritchie R O 1979 Int. Metall. Rev. 20205

Weerasooriya T 1988 in Fracture mechanics; Nineteenth symposium (Philadelphia, USA: American Society of Testing Materials STP 969) 